\title{
Complex Formation of Cyclodextrins with Cationic Polymers
}

\author{
Akira Harada, ${ }^{*}$ Hideaki Adachi, Yoshinori KaWAGUCHI, \\ Miyuko OKADA, and Mikiharu KAMACHI* \\ Department of Macromolecular Science, Faculty of Science, Osaka University, \\ Toyonaka, Osaka 560, Japan
}

(Received October 2, 1995)

\begin{abstract}
Cyclodextrin $(\alpha$-CD) was found to form inclusion complexes with viologen polymers (VP) having octamethylene groups [poly(paraquat-octamethylene)] and longer methylene chains in aqueous solution. The ${ }^{1} \mathrm{H}$ NMR spectra of VP in the presence of $\alpha-C D$ showed that the methylene peaks and peaks of viologen at the polymer end split in two and that the protons on the bipyridinium ring on the main chain shifted toward downfield. Changes of the ${ }^{1} \mathrm{H}$ NMR spectra are time-dependent. It took longer to reach equilibrium as the number of methylene groups increased. The association constant of the complex between $\alpha$-CD and VP was estimated to be $100 \mathrm{M}^{-1} . \alpha-C D$ did not form complexes with VP with hexamethylene groups. $\beta$-CD formed complexes with VP having decamethylene groups and longer methylene chains. The complex formation of $\beta$-CD with VPs is faster than that of $\alpha$-CD with VP. $\gamma$-CD formed complexes with ionene polymers (IP), \{poly[(dimethylimino)alkylene]dibromide\} such as 3,6-ionene and 6,8-ionene to give compounds in the solid state.
\end{abstract}

KEY WORDS Cyclodextrin/Inclusion Complex / Ionic Polymer / Ionene Polymer / Viologen Polymer/

Cyclodextrins (CDs) are a series of cyclic oligosaccharides consisting of six to eight glucose units linked by $\alpha-1,4$ linkages. They are called $\alpha-\beta$-, and $\gamma-\mathrm{CD}$, respectively. They form inclusion complexes with a variety of low molecular weight compounds. ${ }^{1}$ Recently, we found that cyclodextrins form inclusion complexes with various non-ionic polymers to give crystalline compounds in high yield. ${ }^{2}$ For example, $\alpha$-CD forms complexes with poly(ethylene glycol) (PEG) of various molecular weight to give stoichiometric compounds in high yields. ${ }^{3} \beta$-CD did not form complexes with PEG of any molecular weight. However, we found that $\beta$ $\mathrm{CD}$ and $\gamma-\mathrm{CD}$ formed complexes with poly(propylene glycol)(PPG) to give crystalline complexes in high yield ${ }^{4}$ although $\alpha$-CD did not form complexes with PPG of any molecular weight. $\gamma$-CD formed complexes with poly(methyl vinyl ether) (PMVE), although $\alpha$ - and $\beta$-CD did not form complexes with PMVE. ${ }^{5}$ These results indicate that relative sizes of the cavities of CDs and cross-sectional area of these polymers are important in complex formation. We prepared polyrotaxanes in which many $\alpha$-CDs were threaded on a PEG chain. ${ }^{6}$ We prepared tubular polymers starting from polyrotaxane. ${ }^{7}$

This work studies the complex formation of CDs with ionic polymers, such as viologen polymers and ionene polymers. CDs were found to form complexes with such cationic polymers in a selective way. Wenz reported briefly on the complex formation between ionic polymers and CDs in a review as unpublished results. ${ }^{8}$ This paper describes in detail the formation of inclusion complexes of cyclodextrins with such cationic polymers.

\section{RESULTS AND DISCUSSION}

\section{Preparation of Ionene Polymers}

We prepared some viologen polymers (VP) and ionene polymers (IP) starting from dibromo alkanes and $4,4^{\prime}$-bipyridyl or $N, N, N^{\prime}, N^{\prime}$-tetramethyldiaminoalkanes

\footnotetext{
* To whom all correspondence should be addressed.
}

in the usual way. ${ }^{9}$ In our case we need ionene polymers with molecular weight of $200-2000$, because polymers with MW of $200-2000$ are most favorable for the complex formation between CDs and non-ionic polymers. So we used slight excess diamines in preference to dibromides for the polymerization reactions to terminate the reaction by diamine groups. The polymers used for this experiment are depicted in Figure 1.

\section{Complex Formation between $\alpha-C D$ and VP}

Previously, we reported that CDs form complexes with non-ionic polymers, such as poly(ethylene glycol) and poly(propylene glycol), in a selective way to give crystalline compounds when aqueous solutions of these non-ionic polymers are added to saturated aqueous solutions of CDs. ${ }^{2}$ Therefore, we added aqueous solutions of some ionic polymers to saturated aqueous solutions of CDs to see whether crystalline complexes would be formed. CDs did not form insoluble complexes with ionic polymers tested, such as viologen polymers

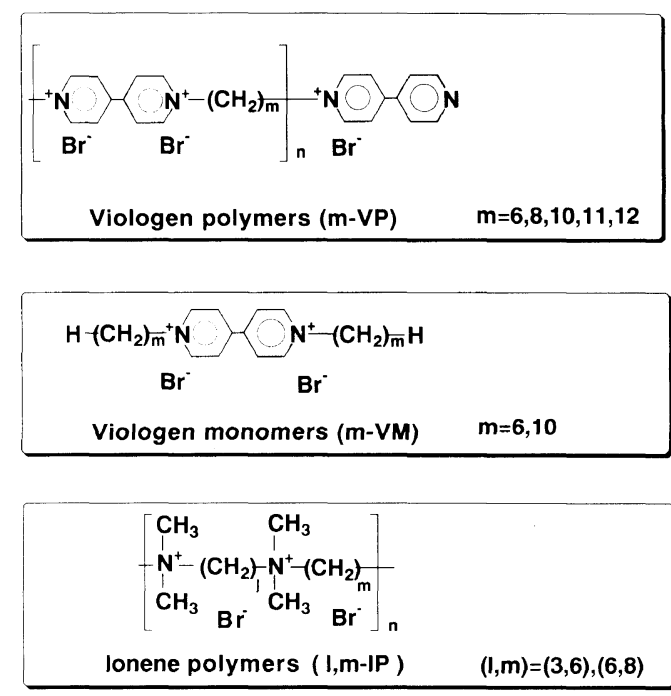

Figure 1. Structures of ionic guests. 
(VP) and polystyrene sulfonates. However, CDs may form inclusion complexes in aqueous solutions. So we measured the ${ }^{1} \mathrm{H}$ NMR spectra of VP in the presence of CDs in $\mathrm{D}_{2} \mathrm{O}$ solutions.

The ${ }^{1} \mathrm{H}$ NMR spectra of 6-VP in the presence of an excess of $\alpha-C D$ showed no changes in components ( $\alpha-C D$ and 6-VP). On the other hand, the ${ }^{1} \mathrm{H}$ NMR spectra of 10 -VP changed on adding $\alpha$-CD. Figure 2 shows the ${ }^{1} \mathrm{H}$ NMR spectra of $10-\mathrm{VP}$ in the absence and presence of $\alpha-C D$. The molar ratio of $\alpha-C D$ to $V P$ in monomeric units is $3: 1$. Two sets of signals are observed for the methylene of (d) and (e), and for (f), (h), (i), and (g) protons on the bipyridinium ring on the end group. Protons (a) and (b) on the bipyridinium ring on the main chain shifted downfield. These results indicate that $\alpha-C D$ formed complexes with 10-VP in aqueous solution and that exchange between free and complexed substrates is slow on a ${ }^{1} \mathrm{H}$ NMR time scale. Similar changes were observed in the ${ }^{1} \mathrm{H}$ NMR spectra of 8 -VP and 12-VP in the presence of $\alpha-C D$. On the other hand $\alpha-C D$ did not form complexes with 6-VP in aqueous solution judging from the NMR spectra.

Measuring ${ }^{1} \mathrm{H}$ NMR spectra of the VPs in the presence of $\alpha$-CD, we found that the ${ }^{1} \mathrm{H}$ NMR spectral changes are time dependent. Figure 3 shows the time dependence of the ${ }^{1} \mathrm{H}$ NMR spectra of $10-\mathrm{VP}$ in the presence of excess $\alpha$-CD. The ${ }^{1} \mathrm{H}$ NMR spectrum of the 10-VP started to change at 1 hour after the addition of $\alpha-C D$ and it took about 12 hours to reach equilibrium. Figure 4 shows the degree of inclusion complex formation of VP with $\alpha-C D$ as a function of time. It took longer to reach equilibrium as the number of methylene groups increased. It took less than 10 hours for 8 -VP to reach equilibrium, whereas it took more than 6 days for 12-VP to come to equilibrium.

Figure 5 shows the effects of the concentration of $\alpha-C D$ on the ${ }^{1} \mathrm{H}$ NMR spectra of $10-\mathrm{VP}$ (at $30^{\circ} \mathrm{C}$ after 3 days).

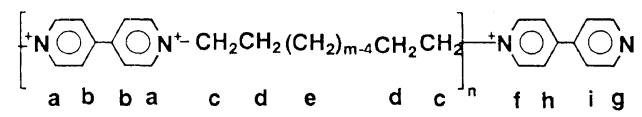

a)

b)

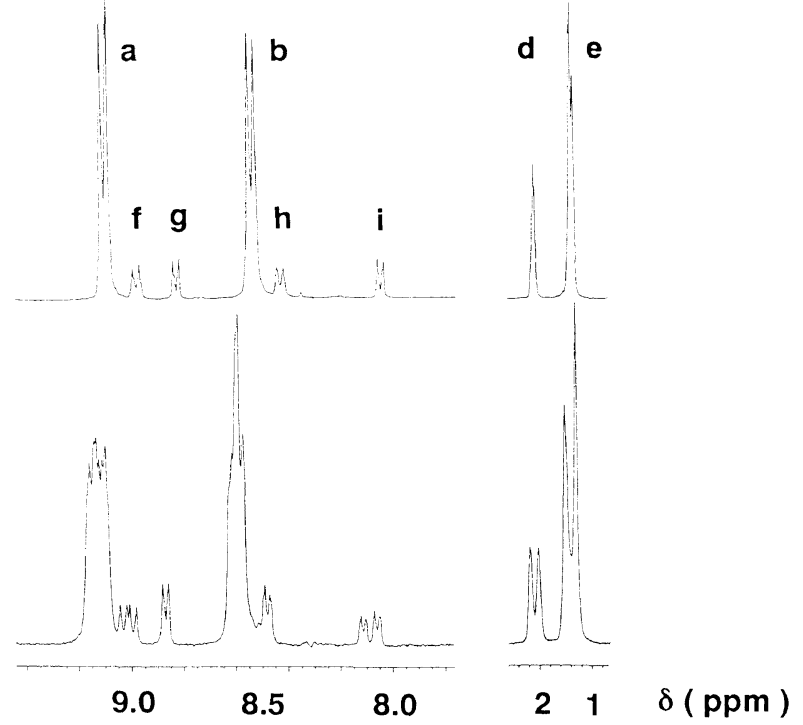

Figure 2. $270 \mathrm{MHz}^{1} \mathrm{H} \mathrm{NMR}$ spectra of 10 -VP in the absence of $\alpha$-CD (a) and $10-\mathrm{VP}$ in the presence of $\alpha-\mathrm{CD}$ (b). The mole ratio of $\alpha-\mathrm{CD}$ to $\mathrm{VP}$ is $3: 1$.
Peaks assigned to the complexed main chain viologen (a, b), those of the methylene groups (c, d, e), and viologen at the chain ends $(f-j)$ increased with the concentration of $\alpha-C D$. Changes of chemical shifts of the peaks of methylene groups (peak d) on adding $\alpha$-CD are similar to those of viologen at the ends (peak i) (Figure 6). These results indicate that not only the end groups but also the main chains of the polymers are included by $\alpha$-CDs.

The stability constant for the complex of $\alpha-C D$ with 10 -VP determined by the ${ }^{1} \mathrm{H}$ NMR spectra is $100 \mathrm{M}^{-1}$. The stability constant for the monomer model compound

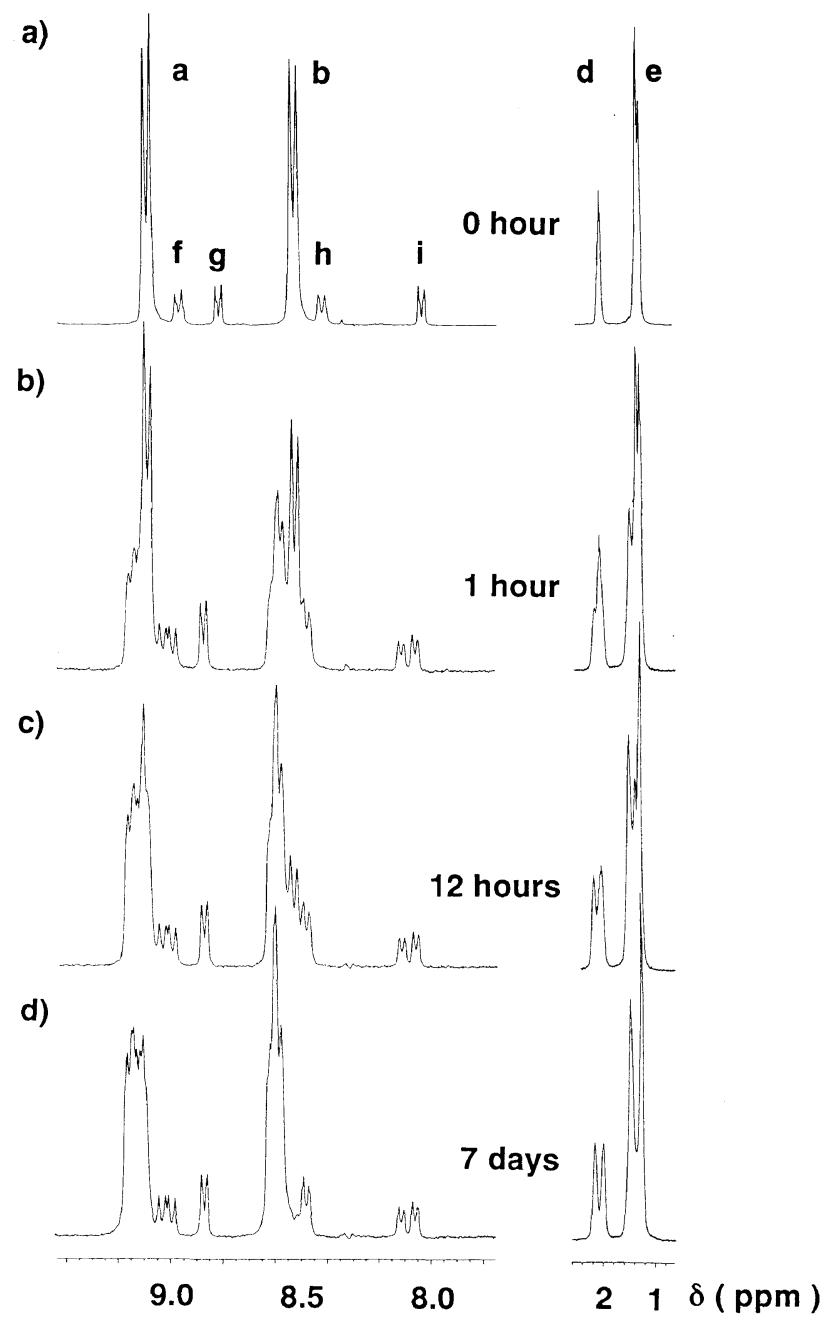

Figure 3. $270 \mathrm{MHz}{ }^{1} \mathrm{H}$ NMR spectra of $10-\mathrm{VP}$ in the presence of $\alpha$-CD after 0 hour (a), 1 hour (b), 12 hours (c), and 7 days (d).

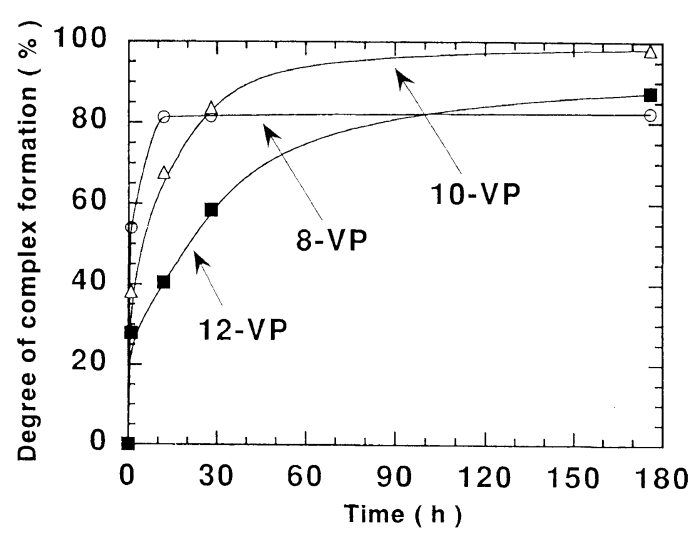

Figure 4. Degree of inclusion complex formation of VP with $\alpha-C D$ as a function of time. 
a)
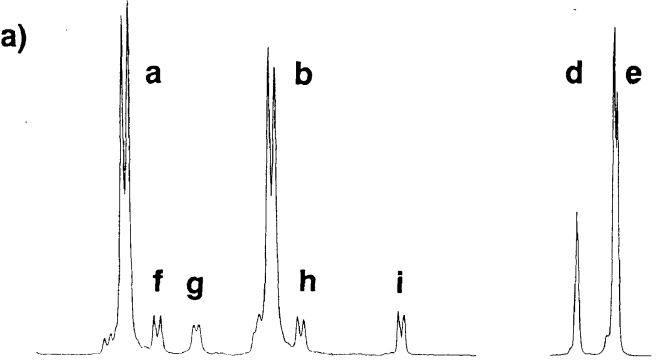

b)

c)

d)

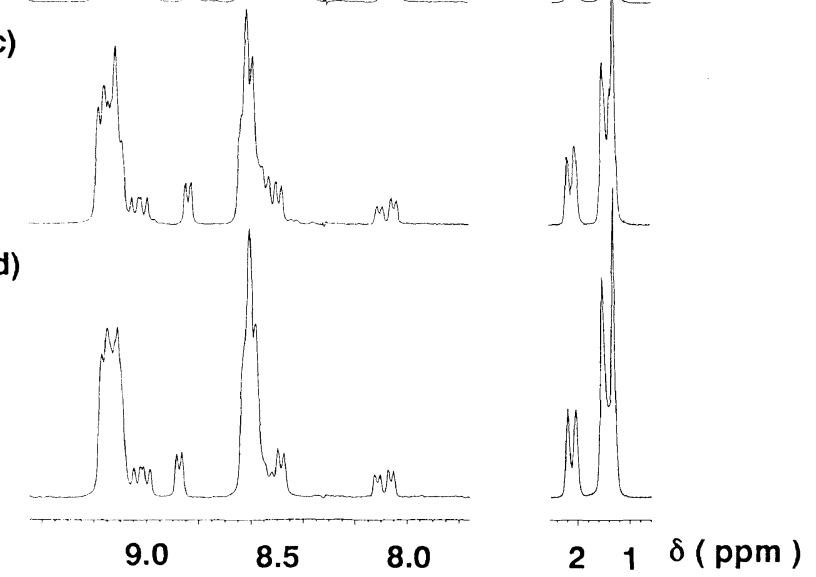

Figure 5. $270 \mathrm{MHz}{ }^{1} \mathrm{H}$ NMR spectra of $10-\mathrm{VP}$ in the presence of $\alpha-\mathrm{CD}$ (at $30^{\circ} \mathrm{C}$ after 3 days). The concentration of $10-\mathrm{VP}$ was $44.4 \mathrm{mM}$. The concentrations of $\alpha-C D$ were $4.5 \mathrm{mM}$ (a), $22.2 \mathrm{mM}$ (b), $44.4 \mathrm{mM}$ (c), and $133 \mathrm{mM}(\mathrm{d})$.

$\left(1,1^{\prime}-\alpha, \omega\right.$-decanediyl)bis $\left(4,4^{\prime}\right.$-bipyridinium $)$ dication $)$ is $1500 \mathrm{M}^{-1}$. The stability constant for the polymer is one tenth that for the monomer model compound. These results indicate that polymer complex formation is more difficult than monomer complex formation. Threading of $\mathrm{CDs}$ is more difficult into the polymer chain than the monomer.

\section{Complex Formation between $\beta-C D$ with $V P$}

The ${ }^{1} \mathrm{H}$ NMR spectra of 6 -VP and 8 -VP in the presence of excess $\beta$-CD showed no changes in components $(\beta$-CD and VP). On the other hand, the ${ }^{1} \mathrm{H}$ NMR spectra of 11 -VP changed on adding $\beta$-CD. Figure 7 shows the ${ }^{1} \mathrm{H}$ NMR spectra of 11-VP in the absence and in presence of 3 molar excess $\alpha-\mathrm{CD}$. The molar ratio of $\beta$-CD to VP monomer units is $3: 1$. Peaks assigned for the methylene chain $(\mathrm{d}, \mathrm{e})$ split in two and those of the viologen units $(a, b)$ shifted downfield. These results indicate that $\beta$-CD formed complexes with 11-VP in aqueous solution and equilibrium is slow on an ${ }^{1} \mathrm{H}$ NMR time scale. Similar changes were observed in the ${ }^{1} \mathrm{H}$ NMR spectra of 12-VP on adding $\beta$-CD. On the other hand $\beta$-CD did not form complexes with 6-VP and 8-VP in aqueous solutions at all, according to NMR spectra. Complex formation between $\beta$-CD and VP is faster than that between $\alpha$-CD and VP. We found that the mixed solutions of $\beta-\mathrm{CD}$ and

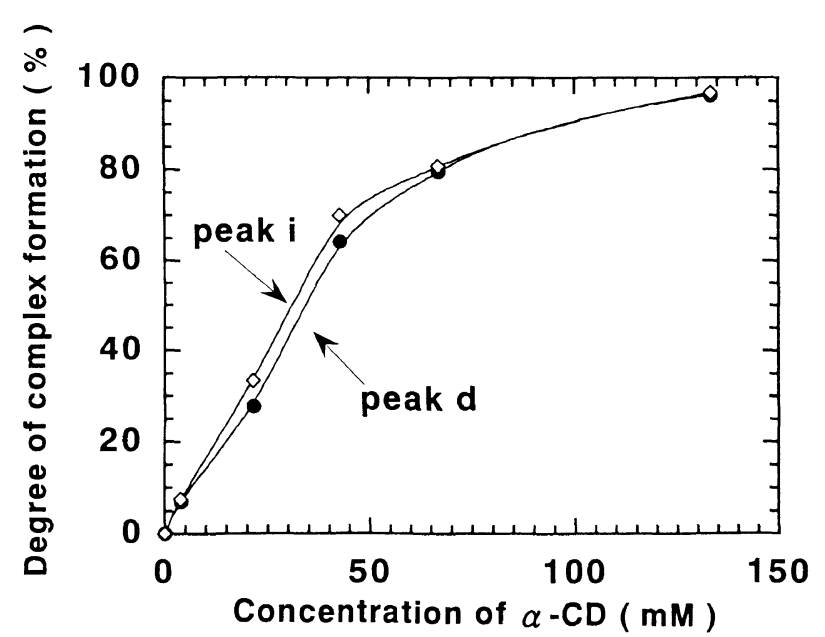

Figure 6. Degree of inclusion complex formation of VP with $\alpha-C D$ as a function of the concentration of $\alpha-\mathrm{CD}$.

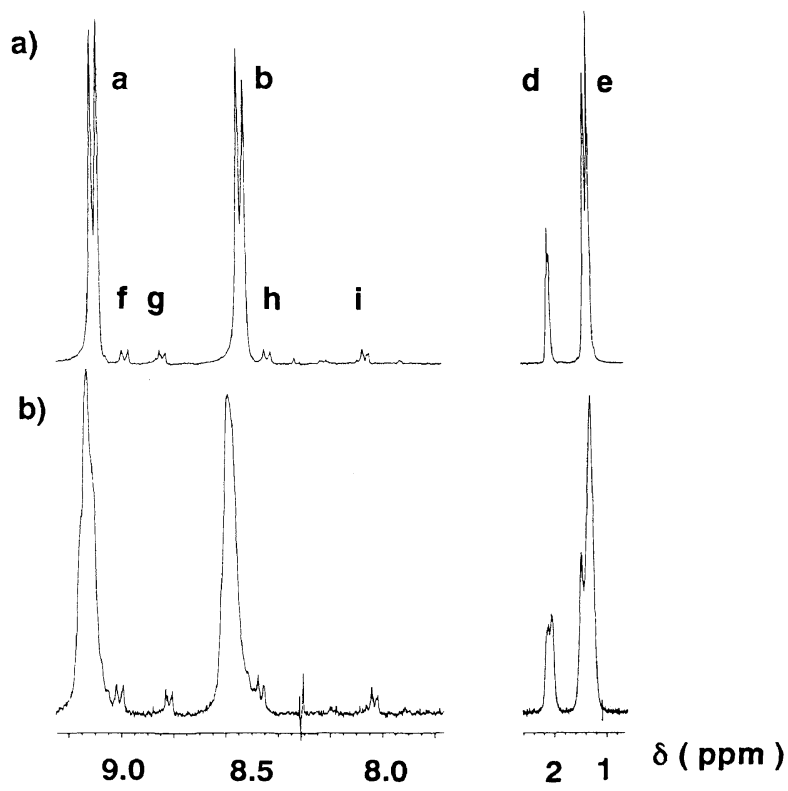

Figure 7. $270 \mathrm{MHz}^{1} \mathrm{H}$ NMR spectra of $11-\mathrm{VP}(\mathrm{a})$, and $\beta$-CD-11-VP (b). The mole ratio of $\beta-\mathrm{CD}$ to VP is $4: 1$.

VP reached equilibrium during sampling for ${ }^{1} \mathrm{H}$ NMR measurements irrespective of the number of methylene groups between viologen groups. This indicates that a $\beta$-CD cavity is large enough for a polymer chain to be threaded in $\mathrm{CD}$ rings and $\alpha-\mathrm{CD}$ cavity is too small for this purpose.

\section{Binding Modes of Complexes}

Figure 8 shows chemical shifts of the viologen groups of VP on adding of $C D$ as a function of alkyl chain length. In the case of $\alpha-\mathrm{CD}, 8$-VP showed the largest shift for peak (a) and (b) and the shifts became smaller as the methylene chain became longer. The viologen moieties are thus most susceptible to the effects of inclusion at octamethylene and the effects of length of the methylene chain on complex formation of CDs become smaller as the chain length increases. In the case of $\beta-\mathrm{CD}, 10-\mathrm{VP}$, and 11-VP showed the largest changes, but the shifts were smaller than those in the case of $\alpha$-CD. These results indicate that $\alpha$-CD binds to the polymer more tightly than $\beta$-CD. 


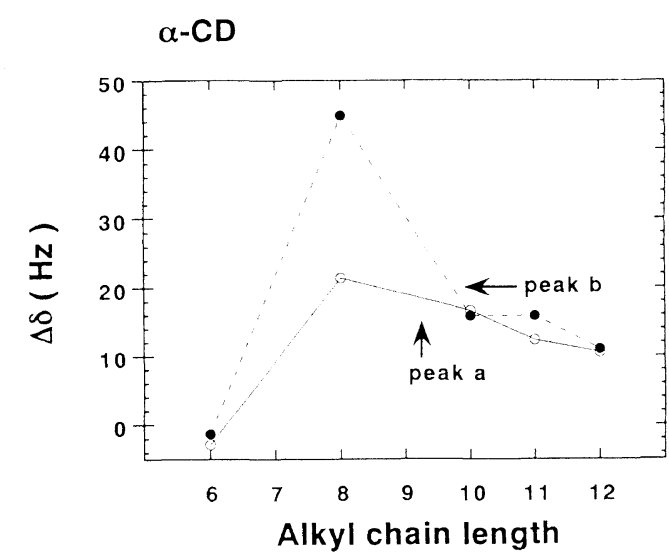

$\beta-C D$

Figure 8. Effects of alkyl chain length on chemical shifts $(\Delta \delta)$ on adding $\alpha$-CD and $\beta$-CD.

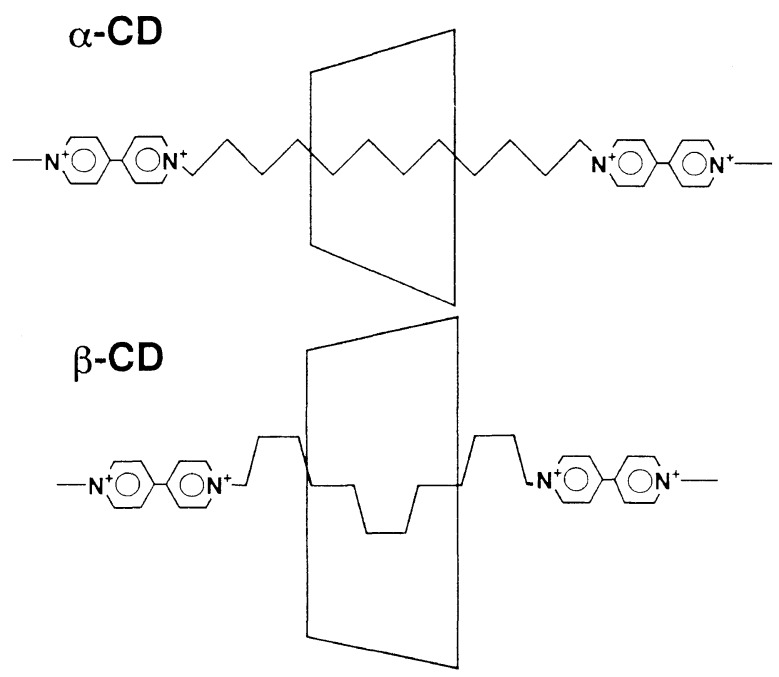

Figure 9. Proposed structures of the $\alpha-C D-V P$ complex (a) and $\beta$-CD-VP complex (b).

Figure 9 shows proposed structures of the $\alpha$-CD $V P$ complex and $\beta$-CD-VP complex. $\beta$-CD accommodates longer chain than $\alpha-C D$ because $\beta-C D$ has larger cavity than $\alpha$-CD.

\section{Complex Formation between $C D$ with VM}

We prepared viologen monomers having alkyl chains at both ends as model compounds (Figure 1). The ${ }^{1} \mathrm{H}$ NMR spectra of 6-VM in the presence of excess $\alpha-C D$ and $\beta$-CD showed no changes in components (CD and $6-\mathrm{VM})$. Although the addition of excess $\beta$-CD to an aqueous solution of $10-\mathrm{VM}$ did not cause change in the ${ }^{1} \mathrm{H}$ NMR spectra of $10-\mathrm{VM}$, the addition of excess $\alpha-C D$ to an aqueous solution of $10-\mathrm{VM}$ broadened each peak and caused downfield shifts of the methyl and methylene groups. This indicates that $\alpha$-CD forms complexes with 10 -VM but with relatively fast exchange between bound and unbound states, although $\beta$-CD did not form complexes with $10-\mathrm{VM}$ judging from the ${ }^{1} \mathrm{H}$ NMR spectra. Figure 10 shows the ${ }^{1} \mathrm{H}$ NMR spectra of the $10-\mathrm{VM}$ in the absence and presence of $\alpha-\mathrm{CD}$.

\section{Complex Formation of $C D$ with Ionene Polymers}

$\alpha-C D$ and $\beta$-CD did not form complexes with 3,6 -ionene and 6,8-ionene polymers in the solid state. However, we found that $\gamma-\mathrm{CD}$ formed complexes with

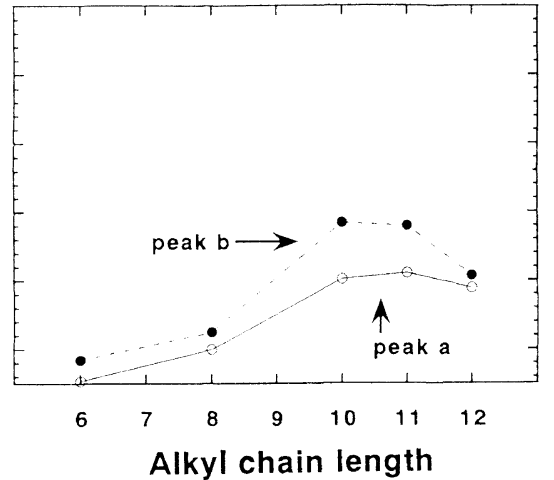

Alkyl chain length

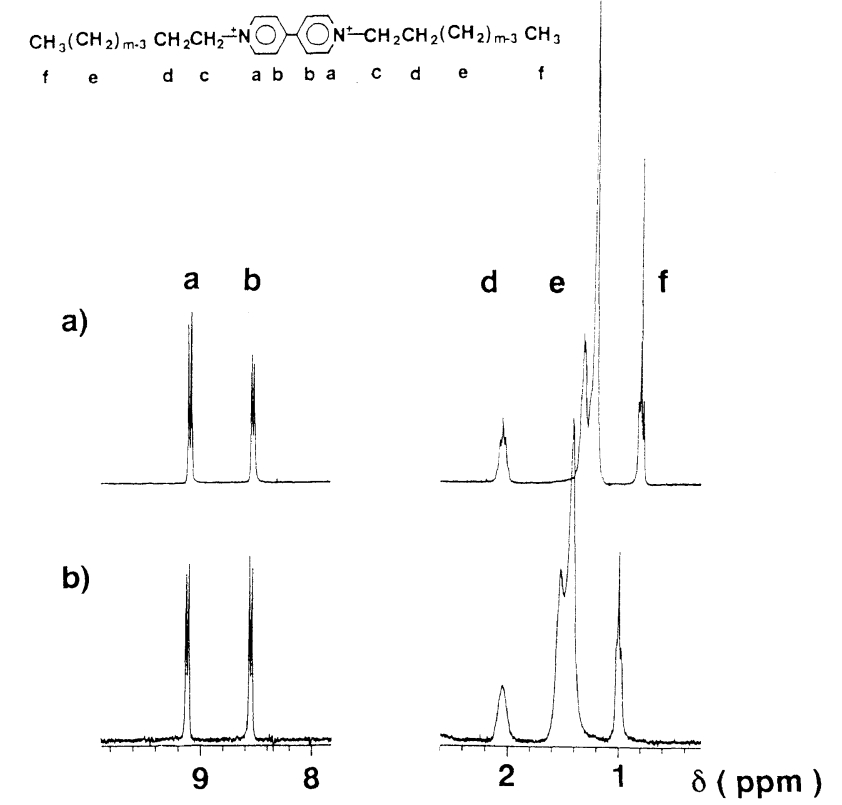

Figure 10. ${ }^{1} \mathrm{H}$ NMR spectra of $10-\mathrm{VM}$ in the absence (a) and presence (b) of $x$-CD $\left(10^{-3} \mathrm{M}\right)$.

ionene polymers (IP), such as 3,6-ionene and 6,8-ionene polymers, to give compounds in the solid state. The complexes are hygroscopic and swell in contact with water. Ionene polymers are large enough to be accommodated in $\gamma$-CD cavity due to the dimethyl groups on the side chain and $\alpha$ - and $\beta$-CD cavities are too small to accommodate ionene polymers. The ${ }^{1} \mathrm{H}$ NMR spectra of these ionene polymers in the presence of $\alpha$ - and $\beta$-CDs did not show complex formation in aqueous solution.

In conclusion, CDs were found to form inclusion complexes not only with non-ionic polymers but also with ionic polymers, such as viologen polymers and ionene polymers. CDs form complexes with ionic polymer in aqueous solution as well as in the solid state depending on the polymers, although CDs form complexes with non-ionic polymers in the solid state. The ionic interactions may prevent CDs from hydrogen bonding between CDs and from crystallization. Complex formation is highly selective. 


\section{EXPERIMENTAL}

\section{Materials}

$\alpha-, \beta-$, and $\gamma$-Cyclodextrins were obtained from Nakarai Tesque Inc. and used after drying at $80^{\circ} \mathrm{C}$ under vacuum with $\mathrm{P}_{2} \mathrm{O}_{5}, 4,4^{\prime}$-Dipyridyl and dibromoalkanes were obtained from Tokyo Kasei Inc.

\section{Preparation of Viologen Polymers (VP)}

Viologen polymers were prepared by treatment of 4,4'-dipyridyl with $N, N, N^{\prime}, N^{\prime}$-tetramethyldiaminoalkanes in DMF in a similar way to the report. ${ }^{9}$ A typical example is as follows.

6-VP: 1,6-dibromohexane $5.0 \mathrm{~g}\left(2.05 \times 10^{-2} \mathrm{~mol}\right)$ and $4,4^{\prime}$-bipyridyl $3.2 \mathrm{~g}\left(2.1 \times 10^{-2} \mathrm{~mol}\right)$ were dissolved in $30 \mathrm{ml}$ of DMF. The mixture was agitated with heating at $100^{\circ} \mathrm{C}$ for 7 hours. An orange precipitate was collected and was dissolved in water and washed with chloroform to remove unreacted starting materials. Yield $80 \%$. The average molecular weight, 4200 .

8 -VP $(M W=3100), 10-\mathrm{VP}(5100)$, and 12-VP(11000) were prepared in a similar manner and obtained in $77 \%$, $95 \%$, and $60 \%$ yield, respectively.

6-VM: $n$-Bromohexane $8.25 \mathrm{~g}\left(5.0 \times 10^{-2} \mathrm{~mol}\right)$ and $4,4^{\prime}$-dipyridyl $0.78 \mathrm{~g}\left(5.1 \times 10^{-3} \mathrm{~mol}\right)$ were dissolved in $20 \mathrm{ml}$ DMF. The mixture was agitated with heating at $100^{\circ} \mathrm{C}$ for 40 hours. An orange precipitate was collected, dissolved in water, and washed with chloroform to remove unreacted starting materials. The product was recrystallized from hexane. Yield $80 \%$.

8-VM and 10-VM were prepared in a similar way.

\section{Measurements \\ ${ }^{1} \mathrm{H}$ NMR spectra were recorded at $270 \mathrm{MHz}$ in $\mathrm{CDCl}_{3}$ and $\mathrm{D}_{2} \mathrm{O}$ on a JEOL JNM GSX-270 spectrometer.}

Chemical shifts were referenced to the solvent values $(\delta$ $4.70 \mathrm{ppm}$ for HOD) or to DSS (3-trimethylsilyl)propionic acid sodium salt using as an external standard.

Degree of complex formation was determined by comparison of the integral of the peaks of the free substrate and that of the bound substrate. The stability constants were determined by the following equation assuming that $\mathrm{CD}$ and a repeating unit of a polymer form a $1: 1$ complex.

$$
K=[\mathrm{VP}]_{0} X /\left\{[\mathrm{VP}]_{0}(1-X)\left([\mathrm{CD}]_{0}-[\mathrm{VP}]_{0} X\right)\right\}
$$

where $[\mathrm{VP}]$ is the concentration of repeating units of the polymer, $[\mathrm{CD}]$ is the concentration of cyclodextrin, and $X$, the degree of complex formation.

\section{REFERENCES}

1. (a) M. L. Bender and M. Komiyama, "Cyclodextrin Chemistry," Springer-Verlag, Berlin, 1978. (b) J. Szejtli, "Cyclodextrin and Their Inclusion Complexes," Akademiai Kiado, Budapest, Hungary, 1982.

2. A. Harada, Polym. News, 18, 358 (1993)

3. (a) A. Harada and M. Kamachi, Macromolecules, 23, 2821 (1990). (b) A. Harada, J. Li, and M. Kamachi, Macromolecules, 26, 5698 (1993).

4. (a) A. Harada and M. Kamachi, J. Chem. Soc., Chem. Commun., 1322 (1990). (b) A. Harada, M. Okada, J. Li, and M. Kamachi, Macromolecules, in press.

5. A. Harada, J. Li, and M. Kamachi, Chem. Lett., 237 (1993).

6. (a) A. Harada, J. Li, and M. Kamachi, Nature, 356, 325 (1992). (b) A. Harada, T. Nakamitsu, J. Li, and M. Kamachi, J. Org. Chem., 58, 7524 (1993). (c) A. Harada, J. Li, and M. Kamachi, J. Am. Chem. Soc., 116, 3192 (1994). (d) G. Wenz and B. Keller, Angew. Chem., Int. Ed., Engl., 31, 197 (1992).

7. A. Harada, J. Li, and M. Kamachi, Nature, 364, 516 (1993).

8. G. Wenz, Angew. Chem., Int. Ed., Engl., 33, 803 (1994).

9. A. D. Wilson and H. J. Prosser, Ed., "Developments in Ionic Polymers 2," Elsevier, London, 1983, p 163. 